The Open Dentistry Journal
CrossMark
Content list available at: www.benthamopen.com/TODENTJ/
DOI: $10.2174 / 1874210601610010438$

RESEARCH ARTICLE

\title{
Influence of Enamel Thickness on Bleaching Efficacy: An In-Depth Color Analysis
}

\author{
Juliana do Carmo Públio ${ }^{1}$, Maria Beatriz Freitas D’Arce ${ }^{1}$, Anderson Catelan ${ }^{1}$, Gláucia Maria Bovi \\ Ambrosano², Flávio Henrique Baggio Aguiar ${ }^{1}$, José Roberto Lovadino ${ }^{1}$ and Débora Alves Nunes \\ Leite Lima ${ }^{1, *}$ \\ ${ }^{I}$ Department of Restorative Dentistry, Piracicaba Dental School, University of Campinas, Av. Limeira, 901, Areião, \\ 13414-903, Piracicaba, SP, Brazil \\ ${ }^{2}$ Department of Community Dentistry, Piracicaba Dental School, University of Campinas, Av. Limeira, 901, Areião, \\ 13414-903, Piracicaba, SP, Brazil
}

\begin{abstract}
This study evaluated the influence of different enamel thicknesses and bleaching agents on treatment efficacy in-depth by spectrophotometry color analysis. Eighty bovine dental fragments were previously stained in black tea solution and randomly assigned into eight groups $(\mathrm{n}=10), 1.75 \mathrm{~mm}$ dentin thickness and different enamel thicknesses as follows: $0.5 \mathrm{~mm}, 1.0 \mathrm{~mm}$ planned, $1.0 \mathrm{~mm}$ unplanned (aprismatic enamel), and absence of enamel. The $10 \%$ carbamide peroxide (CP) and 35\% hydrogen peroxide (HP) bleaching gels were applied on the enamel surface following the manufacturer's recommendations. Color of underlying dentin was evaluated at four times: after staining with tea (baseline) and after each one of the three weeks of bleaching treatment, by CIE $\mathrm{L} * \mathrm{a} * \mathrm{~b} *$ system using reflectance spectrophotometer (CM 700d, Konica Minolta). The $\Delta \mathrm{E}, \Delta \mathrm{L}, \Delta \mathrm{a}$, and $\Delta \mathrm{b}$ values were recorded and subjected to repeated measures ANOVA and Tukey's test $(\alpha=0.05)$. The results showed an increase on lightness $\left(L^{*}\right)$, with decreased redness $\left(\mathrm{a}^{*}\right)$ and yellowness $\left(\mathrm{b}^{*}\right)$. At first and second week, bleaching with CP showed higher whitening effectiveness compared to bleaching with HP and the presence of aprismatic enamel significantly reduced $\Delta \mathrm{E}$ for bleaching with $\mathrm{CP}$. After three weeks of bleaching, few differences were observed between CP and HP groups, and outer enamel layer caused no influence on bleaching effectiveness. Overall, both at-home and in-office bleaching treatments were effective and the presence of aprismatic enamel did not interfere on the whitening efficacy.
\end{abstract}

Keywords: Bleaching agents, Color, Dentin, Enamel, Spectrophotometry, Tooth discoloration.

\section{INTRODUCTION}

Tooth bleaching is a conservative and esthetic treatment for dental discoloration, which acts on the removal of pigments present in the tooth structure, making it whiter [1]. These dental discolorations are result of the deposition of intrinsic or extrinsic chromogenic pigments. The intrinsic discoloration is caused by the incorporation of chromogens components within the tooth structure during odontogenesis or after the tooth eruption. On the other hand, extrinsic discoloration occurs when external chromogens components such as coffee, tea, and wine are deposited on the tooth surface after eruption $[1,2]$.

In the last years, both carbamide and hydrogen peroxide have been used for dental bleaching with various techniques and concentrations. High and low concentrations of peroxides are used for in-office and at-home bleaching treatments, respectively [3]. Bleaching agents haves hydrogen peroxide as active component, which can be applied

\footnotetext{
* Address correspondence to this author at the Department of Restorative Dentistry, Piracicaba Dental School, UNICAMP, Areião, P.O. Box 52, Zip code 13414-903 Piracicaba, SP, Brazil; Tel: +55 19 2106-5339; Fax: +55 19 2106-5218; E-mail: deboralima@fop.unicamp.br
} 
directly to tooth surfaces or produced from chemical reaction of sodium perborate or carbamide peroxide [4].

The penetration and diffusion of bleaching agent are due to enamel permeability, which allows the passage of ions and low-molecular-weight substances into the interior of the tooth through the prisms, reaching the dentin [1]. The light scattering and light absorption are properties of enamel and dentin, respectively [5]. Tooth color is highly influenced by alterations of the color of the subsurface dentin, thus making relevant the investigation of in-depth diffusion of bleaching agent within dental tissues [6]. A previous study [7] showed that bleaching efficacy on enamel and dentin is directly related to application mode and time, as well as to product composition and concentration. During the bleaching treatment, it may be possible to analyze quantitatively the color change using a colorimeter or spectrophotometer [8].

Nevertheless, there have been no studies evaluating the influence of tooth enamel thickness and presence of aprismatic enamel layer on the whitening effectiveness of underlying dentin. Thus, the aim in this study was to evaluate by spectrophotometry analysis the influence of different thicknesses of enamel on bleaching efficacy in depth, according to type of bleaching agent: carbamide peroxide (CP) and hydrogen peroxide (HP).

\section{MATERIALS AND METHODS}

Eighty bovine incisors were stored in a $0.1 \%$ thymol buffered solution, after being collected and disinfected. The select teeth were examined under a 4x magnifying glass (Carl Zeiss, Santo Amaro, SP, Brazil) in order to check for cracks or staining, which could possibly influence the results of this research. If a defect was found, the tooth was discarded and replaced. Then the teeth were stored in distilled water at $4{ }^{\circ} \mathrm{C}$, until the moment of their use.

The teeth crowns were separated from root at the cemento-enamel junction with the use of a double-faced diamond disk (KG Sorensen Ind. Com Ltd, Cotia, SP, Brazil) mounted on a low-speed dental hand piece under constant water irrigation. The blocks were obtained using a diamond-cutting disc coupled to a precision saw (Isomet 1000; Buehler, Lake Buff, IL, USA).

Two cuts were performed in both mesio-distal and cervical-incisal directions, resulting in one block of each tooth originated from most cervical region of the crown. Thereby, the enamel-dentin blocks with $4 \mathrm{~mm}$ length and $4 \mathrm{~mm}$ width were obtained from buccal surfaces of the teeth.

The enamel and opposite dentine surfaces were abraded with 600- and 1200-grit silicon carbide (SiC) abrasive papers (CarbiMet 2; Buehler, Lake Bluff, IL, USA) using a polishing machine (Arotec Ind. Com., Cotia, SP, Brazil), under constant water irrigation. The dentin was abraded until achieving $1.75 \mathrm{~mm}$ of thicknesses for all groups, and the enamel was abraded until achieving the different thicknesses for each experimental group [0.5 mm planned (0.5E), 1.0 $\mathrm{mm}$ planned (1E), $1.0 \mathrm{~mm}$ unplanned - aprismatic (1AE), and absence of enamel (D)]. The standardization of the enamel thickness was obtained using a digital caliper (Carl Mahr Esslingen GmbH, Göttingen, Germany).

In the interval between each application of abrasive paper, the specimens were cleaned with distilled water using an ultrasonic bath (T7 Type, CT Model; Thornton-Inpec Electronic Ltd, Vinhedo, SP, Brazil). Then each specimen was marked with a diamond bur \#1012 (KG Sorensen Ind. Com Ltd, Cotia, SP, Brazil) on one side to standardize the specimen position on the spectrophotometer.

The specimen staining was performed by immersion the tooth blocks in a black tea solution, which was changed at every $24 \mathrm{~h}$ for 6 days, the enamel and dentin surface remained in contact with the solution during whole time. The tea solution was produced by mixing up $100 \mathrm{~mL}$ of distilled boiled water for $5 \mathrm{~min}$ with $1.6 \mathrm{~g}$ of black tea (Leão Junior S.A., Curitiba, PR, Brazil) infused for $5 \mathrm{~min}$. After this period of immersion in the staining solution, the specimens were stored in artificial saliva [9] during two weeks and daily changed for color stabilization. Prior spectrophotometer reading, the black tea dregs formed on the enamel and dentin surfaces were removed by a single operator using a rubber cup with a mixture of pumice and water (2:1 ratio) at low speed for $30 \mathrm{~s}$ each side [10].

The color analyses were performed on the underlying dentin (opposite to enamel surface) at four times: after staining with black tea (baseline) and after each of the three weeks of bleaching. The specimens were placed in a Teflon device (sample-holder) inside a light cabin (GTI Mini Matcher MM1e; GTI Graphic Technology Inc., Newburgh, NY, USA) to standardize the ambient light during color measurement process, and then specimens were subjected to reading using a spectrophotometer (CM-700d; Konica Minolta Investment Ltd Sensing Business Division, Shanghai, China), previously calibrated. The values obtained were quantified on the CIE Lab system as three coordinates $\left(\mathrm{L}^{*}, \mathrm{a}^{*}, \mathrm{~b}^{*}\right)$ that define the color of an object within a three-dimensional color space. A microcomputer using On Color QC Lite software (Konica Minolta, Japan) was used to generate spectral measurements as a function of wavelength for data processing 
and analysis. The coordinate $\mathrm{L}^{*}$ represents the degree of lightness ranging from 0 (black) to 100 (white), the coordinate $a^{*}$ evaluates the presence of pigments red (positive $a^{*}$ ) and green (negative $a^{*}$ ), and likewise the coordinate $b^{*}$ refers to the pigments yellow (positive $b^{*}$ ) and blue (negative $b^{*}$ ) present in the specimens $[1,5]$. The $L^{*} a^{*} b^{*}$ system allows the numeric definition of a color as well as the difference between two colors using the following formula:

$$
\Delta \mathrm{E}=\left[\left(\mathrm{L}_{1}-\mathrm{L}_{0}\right)^{2}+\left(\mathrm{a}_{1}-\mathrm{a}_{0}\right)^{2}+\left(\mathrm{b}_{1}-\mathrm{b}\right)^{2}\right]^{1 / 2} .
$$

For bleaching procedures, dental blocks were fixed in a device and approximately $1.0 \mathrm{~mm}$ of bleaching agent was applied on enamel surface. The bleaching procedures were performed according to the following protocols $(n=10)$ :

Groups 1, 2, 3, and 4: 10\% CP (Whiteness Perfect; FGM Dental Products, Joinville, SC, Brazil). The gel was applied on enamel surface and stored at $37^{\circ} \mathrm{C}$ for $4 \mathrm{~h}$. The bleaching was performed daily for 21 days.

Groups 5, 6, 7, and 8: 35\% HP (Whiteness HP Maxx; FGM Dental Products). The gel was applied on enamel surface for $45 \mathrm{~min}$. Three bleaching sessions were accomplished, with a 7-day interval.

The CP gel was applied once daily for $4 \mathrm{~h}$, whereas the HP gel was applied three times of 15 min each for a total time of $45 \mathrm{~min}$. At every application, the gel was removed using cotton tipped applicators (Johnson \& Johnson, São José dos Campos, SP, Brazil). At the end of the bleaching session, the specimens were washed thoroughly in running water, dried with absorbing paper, and stored in artificial saliva at a temperature of $37^{\circ} \mathrm{C}$. After the end of each bleaching session, there was a 24-h-interval of storage of the specimens in artificial saliva aiming their rehydration before to perform the color readings.

Following exploratory data analysis, the variables $\Delta \mathrm{E}, \Delta \mathrm{L}, \Delta \mathrm{a}$ and $\Delta \mathrm{b}$ were subjected to 2-way analysis of variance (ANOVA) for repeated measures and Tukey's test at a significance level of 0.05 . The factors considered were bleaching agent (in 2 levels) and enamel thickness (in 4 levels).

\section{RESULTS}

Tables 1-4 present $\Delta \mathrm{E}, \Delta \mathrm{L}, \Delta \mathrm{a}$, and $\Delta \mathrm{b}$ values according to bleaching agent and enamel thickness within each evaluated time: baseline $\mathrm{x} 1^{\text {st }}$ week of bleaching $(\Delta \mathrm{E} 1, \Delta \mathrm{L} 1, \Delta \mathrm{a} 1$, and $\Delta \mathrm{b} 1)$, baseline $\mathrm{x} 2^{\text {nd }}$ week of bleaching $(\Delta \mathrm{E} 2$, $\Delta \mathrm{L} 2, \Delta \mathrm{a} 2$, and $\Delta \mathrm{b} 2)$, and baseline $\times 3^{\text {rd }}$ week of bleaching $(\Delta \mathrm{E} 3, \Delta \mathrm{L} 3, \Delta \mathrm{a} 3$, and $\Delta \mathrm{b} 3)$.

Table 1. $\Delta \mathbf{E}$ means (standard deviation) according to bleaching agent and enamel thickness for each time evaluated.

\begin{tabular}{|c|c|c|c|c|}
\hline \multirow{2}{*}{ Bleaching agent } & \multirow{2}{*}{ Enamel thickness } & & Time & \\
\hline & & $\Delta \mathrm{E} 1$ & $\Delta \mathbf{E} 2$ & $\Delta \mathbf{E} 3$ \\
\hline \multirow{4}{*}{$\begin{array}{l}10 \% \text { Carbamide } \\
\text { Peroxide }\end{array}$} & $0 \mathrm{~mm}$ enamel (D) & $* 24.74(5.22) \mathrm{a}$ & $* 34.60(5.45) \mathrm{a}$ & $41.16(5.95) \mathrm{a}$ \\
\hline & $0.5 \mathrm{~mm}$ enamel $(0.5 \mathrm{E})$ & $* 19.03(3.06) \mathrm{b}$ & $* 27.77(3.97) \mathrm{b}$ & $36.80(3.08) \mathrm{ab}$ \\
\hline & $1 \mathrm{~mm}$ planned enamel $(1 \mathrm{E})$ & $* 16.64(1.63) \mathrm{b}$ & $* 25.98(3.43) b c$ & *34.88(3.38) b \\
\hline & $1 \mathrm{~mm}$ unplanned enamel (aprismatic) (1AE) & $11.19(3.18) \mathrm{c}$ & $20.44(5.21) \mathrm{c}$ & $31.55(4.35) \mathrm{b}$ \\
\hline \multirow{4}{*}{$\begin{array}{l}35 \% \text { Hydrogen } \\
\text { Peroxide }\end{array}$} & $0 \mathrm{~mm}$ enamel (D) & $13.39(2.85) \mathrm{a}$ & $28.43(3.93) \mathrm{a}$ & $37.31(4.63) \mathrm{a}$ \\
\hline & $0.5 \mathrm{~mm}$ enamel $(0.5 \mathrm{E})$ & $6.81(1.68) \mathrm{b}$ & $16.49(2.78) b$ & $31.48(3.42) \mathrm{b}$ \\
\hline & $1 \mathrm{~mm}$ planned enamel (1E) & $6.96(2.87) \mathrm{b}$ & $16.64(3.85) \mathrm{b}$ & $25.14(2.65) \mathrm{c}$ \\
\hline & $1 \mathrm{~mm}$ unplanned enamel (aprismatic) (1AE) & $8.03(1.93) b$ & $14.86(3.47) \mathrm{b}$ & $28.26(4.12) b c$ \\
\hline
\end{tabular}

Means followed by different lowercase letters comparing thickness within bleaching agent and evaluated time indicate significant difference $(p \leq$ $0.05)$. *It differs from $35 \%$ hydrogen peroxide in the same thickness and time $(p \leq 0.05)$.

The data shows that the presence of at least $0.5 \mathrm{~mm}$ enamel reduced the bleaching effectiveness (higher $\Delta \mathrm{E})$ at all time points and for both bleaching agents $(p<0.05)$. At times $\Delta \mathrm{E} 1$ and $\Delta \mathrm{E} 2$, groups treated with $\mathrm{CP}$ showed higher $\Delta \mathrm{E}$ than HP, except group "E1A". Therefore, presence of the aprismatic enamel surface reduced significantly $\Delta \mathrm{E}$ values in $\mathrm{CP}$ treated specimens. In general, there was little difference between specimens with 0.5 and $1.0 \mathrm{~mm}$ of enamel in terms of $\Delta \mathrm{E}$ means. At time $\Delta \mathrm{E} 3$, few differences were observed between $\mathrm{CP}$ and HP treatments and this outer enamel layer did not affect $\Delta \mathrm{E}$ treated with HP and CP.

The findings in Table 2 showed that for all evaluated times and bleaching products, group " $\mathrm{D}$ " had higher $\Delta \mathrm{L}$ means, compared to other groups $(p<0.05)$. At times $\Delta \mathrm{L} 1$ and $\Delta \mathrm{L} 2$, groups treated with $\mathrm{CP}$ showed higher $\Delta \mathrm{L}$ values in relation to HP, expect group "E1A" at time $\Delta \mathrm{L} 1$. At time $\Delta \mathrm{L} 3$, only the group "E1" treated with $\mathrm{CP}$ had higher $\Delta \mathrm{L}$ mean than HP. 
Table 2. $\Delta \mathrm{L}$ means (standard deviation) according to bleaching agent and enamel thickness for each time evaluated.

\begin{tabular}{|c|c|c|c|c|}
\hline \multirow{2}{*}{ Bleaching agent } & Enamel thickness & & Time & \\
\cline { 2 - 5 } & & $\Delta \mathbf{L 1}$ & $\Delta \mathbf{L 2}$ & $\Delta \mathbf{L 3}$ \\
\hline \multirow{4}{*}{$\begin{array}{c}10 \% \text { Carbamide } \\
\text { Peroxide }\end{array}$} & $0.5 \mathrm{~mm}$ enamel (D) & $* 15.65(4.17) \mathrm{a}$ & $* 23.40(4.23) \mathrm{a}$ & $32.24(4.53) \mathrm{a}$ \\
\cline { 2 - 5 } & $1 \mathrm{~mm}$ planned enamel (1E) & $* 10.30(2.89) \mathrm{b}$ & $* 15.89(3.45) \mathrm{b}$ & $25.95(2.59) \mathrm{b}$ \\
\cline { 2 - 5 } & $1 \mathrm{~mm}$ unplanned enamel (aprismatic) $(1 \mathrm{AE})$ & $5.47(2.15) \mathrm{c}$ & $* 10.58(3.70) \mathrm{c}$ & $19.75(3.21) \mathrm{c}$ \\
\hline \multirow{3}{*}{$\begin{array}{c}35 \% \text { Hydrogen } \\
\text { Peroxide }\end{array}$} & $0.5 \mathrm{~mm}$ enamel (D) & $8.54(2.32) \mathrm{a}$ & $19.58(3.48) \mathrm{a}$ & $28.02(4.32) \mathrm{a}$ \\
\cline { 2 - 5 } & $0.5 \mathrm{~mm}$ enamel $(0.5 \mathrm{E})$ & $4.32(1.24) \mathrm{b}$ & $9.62(3.00) \mathrm{b}$ & $21.94(2.08) \mathrm{b}$ \\
\cline { 2 - 5 } & $1 \mathrm{~mm}$ planned enamel (1E) & $4.71(2.55) \mathrm{b}$ & $9.88(3.50) \mathrm{b}$ & $14.84(3.50) \mathrm{c}$ \\
\cline { 2 - 5 } & $1 \mathrm{~mm}$ unplanned enamel (aprismatic) $(1 \mathrm{AE})$ & $4.46(1.63) \mathrm{b}$ & $7.16(2.20) \mathrm{c}$ & $19.54(2.89) \mathrm{bc}$ \\
\hline
\end{tabular}

Means followed by different lowercase letters comparing thickness within bleaching agent and evaluated time indicate significant difference $(p \leq$ $0.05) . *$ It differs from $35 \%$ hydrogen peroxide in the same thickness and time $(p \leq 0.05)$.

The red-green $\left(\mathrm{a}^{*}\right)$ coordinate data are illustrated in Table $3(\Delta \mathrm{a})$; at the time $\Delta \mathrm{a}$, CP presented the lowest $\Delta \mathrm{a}$ values for groups "E0.5" and "E1" compared to HP. At time $\Delta \mathrm{a} 2$, CP had lower means than HP, except for group "D". At time $\Delta \mathrm{a} 3, \Delta \mathrm{a}$ values were similar for groups treated with $\mathrm{CP}$ and $\mathrm{HP}$.

Table 3. $\Delta$ a means (standard deviation) according to bleaching agent and enamel thickness for each time evaluated.

\begin{tabular}{|c|c|c|c|c|}
\hline \multirow{2}{*}{ Bleaching agent } & \multirow{2}{*}{ Enamel thickness } & & Time & \\
\hline & & $\Delta \mathbf{a} 1$ & $\Delta \mathbf{a 2}$ & $\Delta \mathbf{a} 3$ \\
\hline \multirow{4}{*}{$\begin{array}{l}10 \% \text { Carbamide } \\
\text { Peroxide }\end{array}$} & $0 \mathrm{~mm}$ enamel (D) & $-5.54(1.88) \mathrm{a}$ & $-4.13(3.01) b$ & $-0.14(2.99) b$ \\
\hline & $0.5 \mathrm{~mm}$ enamel $(0.5 \mathrm{E})$ & $*_{-7.36}(2.13) \mathrm{a}$ & *-8.49 (2.36) a & $-5.89(2.51) \mathrm{a}$ \\
\hline & $1 \mathrm{~mm}$ planned enamel $(1 \mathrm{E})$ & *-6.08 (1.74) a & *-7.41 (3.09) a & $-6.18(3.51) \mathrm{a}$ \\
\hline & $1 \mathrm{~mm}$ unplanned enamel (aprismatic) (1AE) & $-5.81(0.78) \mathrm{a}$ & *-9.03 (1.48) a & $-9.61(2.00) \mathrm{a}$ \\
\hline \multirow{4}{*}{$\begin{array}{l}35 \% \text { Hydrogen } \\
\text { Peroxide }\end{array}$} & $0 \mathrm{~mm}$ enamel (D) & $-3.80(1.09) \mathrm{a}$ & $-4.33(2.23) b$ & $-2.00(3.34) b$ \\
\hline & $0.5 \mathrm{~mm}$ enamel $(0.5 \mathrm{E})$ & $-2.62(0.71)$ a & $-5.41(1.62) \mathrm{a}$ & $-5.24(1.92) a b$ \\
\hline & $1 \mathrm{~mm}$ planned enamel $(1 \mathrm{E})$ & $-2.17(1.00) \mathrm{a}$ & $-5.15(2.44) \mathrm{a}$ & $-6.71(3.77) \mathrm{a}$ \\
\hline & $1 \mathrm{~mm}$ unplanned enamel (aprismatic) (1AE) & $-4.02(0.95) \mathrm{a}$ & $-7.07(2.06) \mathrm{a}$ & $-6.59(2.07) \mathrm{a}$ \\
\hline
\end{tabular}

Means followed by different lowercase letters comparing thickness within bleaching agent and evaluated time indicate significant difference $(p \leq$ $0.05)$. *It differs from $35 \%$ hydrogen peroxide in the same thickness and time $(p \leq 0.05)$.

The $\Delta \mathrm{b}$ values are present in Table $4, \mathrm{CP}$ showed lower means with statistical difference in relation to HP, except for the group "E1A" at time $\Delta \mathrm{b} 1$. For beaching agents, at times $\Delta \mathrm{b} 1$ and $\Delta \mathrm{b} 2$ the group "D" had lower mean compared to other groups $(p<0.05)$. At time $\Delta \mathrm{b} 3$, this group was significantly different only of "E1A" for CP and did not differ only of group "E0.5" when treated with HP.

Table 4. $\Delta$ b means (standard deviation) according to bleaching agent and enamel thickness for each time evaluated.

\begin{tabular}{|c|c|c|c|c|}
\hline \multirow{2}{*}{ Bleaching agent } & \multirow{2}{*}{ Enamel thickness } & & Time & \\
\hline & & $\Delta \mathbf{b} 1$ & $\Delta \mathbf{b 2}$ & $\Delta \mathbf{b 3}$ \\
\hline \multirow{4}{*}{$\begin{array}{l}10 \% \text { Carbamide } \\
\text { Peroxide }\end{array}$} & $0 \mathrm{~mm}$ enamel (D) & $*_{-1} 18.18(3.61) \mathrm{a}$ & *-24.94 (3.85) a & $*-25.20(5.23) \mathrm{a}$ \\
\hline & $0.5 \mathrm{~mm}$ enamel $(0.5 \mathrm{E})$ & $*_{-13.87(2.62) b}$ & $*-20.84(3.38) b$ & *-25.18 (3.18) a \\
\hline & $1 \mathrm{~mm}$ planned enamel $(1 \mathrm{E})$ & *-11.87 (1.65) b & *-18.65 (2.99) bc & *-23.59 (3.04) ab \\
\hline & $1 \mathrm{~mm}$ unplanned enamel (aprismatic) (1AE) & $-7.70(2.70) \mathrm{c}$ & *-14.70 (4.50) c & $*-22.49(3.65) b$ \\
\hline \multirow{4}{*}{$\begin{array}{l}35 \% \text { Hydrogen } \\
\text { Peroxide }\end{array}$} & $0 \mathrm{~mm}$ enamel (D) & $-9.46(2.07) \mathrm{a}$ & $-19.90(3.13) \mathrm{a}$ & $-23.79(5.68) \mathrm{a}$ \\
\hline & $0.5 \mathrm{~mm}$ enamel $(0.5 \mathrm{E})$ & $-4.47(1.33) b$ & $-11.97(2.02) b$ & $-21.86(2.95) \mathrm{ab}$ \\
\hline & $1 \mathrm{~mm}$ planned enamel $(1 \mathrm{E})$ & $-4.29(2.07) b$ & $-11.84(3.26) b c$ & $-18.57(2.17) b$ \\
\hline & $1 \mathrm{~mm}$ unplanned enamel (aprismatic) (1AE) & $-5.16(1.49) b$ & $10.59(3.37) \mathrm{c}$ & $-19.19(3.11) b$ \\
\hline
\end{tabular}

Means followed by different lowercase letters comparing thickness within bleaching agent and evaluated time indicate significant difference $(p \leq$ 0.05). *It differs from $35 \%$ hydrogen peroxide in the same thickness and time $(p \leq 0.05)$. 


\section{DISCUSSION}

This study evaluated the influence of different enamel thicknesses and bleaching agents on the whitening efficacy in-depth, by using bovine tooth block previously stained with black tea. It reported that human and bovine teeth exhibit similar behavior during bleaching [11]. This behavior is due to morphological similarities and physicochemical characteristics between both enamel and dentin tooth hard tissues of human and bovine teeth, making them an alternative experimental source $[12,13]$.

In dental bleaching, gels containing both $\mathrm{CP}$ and HP are used, which were applied directly on enamel surface of specimens. Although reaction products involving CP and HP are same, i.e., oxygen-free radicals, studies have reported that action mechanism of these two agents is different, since the peroxide breakdown reaction resulting in radical releasing occurs differently. $\mathrm{CP}$ in contact with tooth surface dissociates into HP and urea. Subsequently, the urea continues to decompose into carbon dioxide $\left(\mathrm{CO}_{2}\right)$ and ammonia $\left(\mathrm{NH}_{3}{ }^{+}\right)$. On the other hand, HP dissociates into free radicals, which oxidize long-chain organic molecules responsible by discoloration of dental tissue cleaving their double bonds $[14,15]$.

With the purpose of analyzing bleaching efficacy, $\Delta \mathrm{E}$ values were calculated as they show the numerical value of tooth color change between different times [8]. At times $\Delta \mathrm{E} 1$ and $\Delta \mathrm{E} 2$, the highest color change was found for groups treated with CP compared to HP, except unplanned enamel group " $1 \mathrm{AE}$ ". The presence of ammonia in CP elevates the $\mathrm{pH}$ making it alkaline, and thus potentiates the bleaching action [16]. Furthermore, presence of carbopol thickener, a water-soluble polymer, in its composition increases the half-life of CP and gradually releases HP, followed by its dissociation into free radicals [17]. Dietschi et al. [18] reported that home bleaching with CP has shown greater efficacy in whitening deeper structures such as dentin, due to the continuous and long release of hydrogen peroxide radicals, corroborating with the findings of this investigation.

In comparing groups according to bleaching agent within each evaluation time, it can be observed that group with absence of enamel (group " $\mathrm{D}$ ") showed the highest $\Delta \mathrm{E}$ (Table 1). In this regard, enamel acts as a filter in the ions diffusion and substances through tooth due to the presence of prisms, so bleaching agents applied directly on the dentin surface have their action facilitated, allowing a higher color change. Eimar et al. [4] observed that oxidation reaction occurs in just organic content, but clinically the bleaching treatment should not be performed directly on dentin tissue.

At $\triangle \mathrm{E} 1$ time, the presence of aprismatic enamel " $1 \mathrm{AE}$ " influenced the $\mathrm{CP}$ bleaching, showing less color change in comparison with group without aprismatic enamel "1E". Enamel is formed by apatite crystals arranged as layers of prisms in different directions [19]. So, aprismatic layer is found in the most superficial area of enamel, in which crystals are arranged parallel to each other and perpendicular to enamel surface. In prismatic layer, however, crystals are found at different angles in a three-dimensional array and with irregular appearance [20,21]. The aprismatic outer layer is more mineralized due to its higher amount of inorganic content, which makes surface denser and less permeable when compared to prismatic enamel [22]. This fact possibly interfered in CP penetration into tooth, but after three bleaching sessions this layer no affected bleaching effectiveness.

Nevertheless, presence of aprismatic layer did not affect bleaching in these same groups treated with HP. Probably due to its action mechanism and larger amounts of free radicals. The low molecular weight of HP facilitates its diffusion into tooth through the enamel prisms and organic matrix, towards dentin-enamel junction thereafter reaching the dentin. Moreover, viscosity of HP is lower than CP, because this last has carbopol in its composition increasing viscosity.

$\mathrm{CP}$ takes a longer dissociation of its products until HP release at low concentration $(\sim 3.6 \%)$. On the other hand, as soon as HP gel is applied on tooth structure it dissociates, and such high concentration of ions will result in a quick whitening action. However, at time $\Delta \mathrm{E} 3$ there was no difference between $\mathrm{CP}$ and HP, except for "1E" group. This finding can be directly associated with consecutive applications of bleaching agents. According to Hanks et al. (1993) [23] the diffusion of HP through tooth is related to number of applications, allowing longer exposure of the tooth to peroxide. Bernardon et al. [24] observed clinically that degree of bleaching achieved by the at-home and in-office techniques was similar. Also, Dietschi et al. [7] verified that after recommended number of applications, HP similar whitening effectiveness compared to $\mathrm{CP}$, thus bleaching effect had as main factor the contact time with tooth surface.

This study also evaluated three-color coordinates $(\Delta \mathrm{L}, \Delta \mathrm{a}$, and $\Delta \mathrm{b})$ separately. Among these coordinates, $\mathrm{L}^{*}$ is the most important parameter to evaluate dental bleaching. Considering the human eye, changes in lightness are more easily detected than chromatic coordinates $\left(a^{*}\right.$ and $\left.b^{*}\right)[18,25]$, which is a feature of great clinical relevance.

As regards the lightness $(\Delta \mathrm{L})$ coordinate (Table 2 ), the groups had behavior very similar to those of $\Delta \mathrm{E}$. The groups 
treated with $\mathrm{CP}$ obtained higher $\Delta \mathrm{L}$ compared to HP at times $\Delta \mathrm{L} 1$ and $\Delta \mathrm{L} 2$, except for the group "1AE" at $\Delta \mathrm{L} 1$. The group " $\mathrm{D}$ " at all times for both bleaching agents showed higher $\Delta \mathrm{L}$ differing from the other groups. The $\Delta \mathrm{E}$ and $\Delta \mathrm{L}$ are directly related one another, since $\Delta \mathrm{L}$ values are included in the formula of $\Delta \mathrm{E}$. The bleaching products acted removing the chromogens from tooth structure, which facilitate their diffusion trough dentin in-depth and thus increase the lightness $[5,26]$.

Analyzing a* coordinate (Table 3), for groups treated with CP and HP there was significant difference among them at times $\Delta \mathrm{a} 1$ and $\Delta \mathrm{a} 2$. However, at time $\Delta \mathrm{a} 3$ was not observed difference between groups regarding the bleaching agents. Previous studies $[1,6]$ observed decrease in a* color parameter, ranging from positive to negative values. Thus, specimens towards green color after bleaching sessions due to loss of red pigments obtained from tea staining [1], corroborating with findings of present investigation.

During the bleaching sessions was observed decrease in $\mathrm{b}^{*}$ coordinate (Table 4) towards blue color, in accordance with Sulieman et al. [1]. Thus, yellow pigments present in tooth are broken in smaller molecules, making it clearer. As regards the time, $\Delta \mathrm{b} 1$ and $\Delta \mathrm{b} 2$ followed the similar behavior of $\Delta \mathrm{L}$, in agreement with Bengel [27] that verified major changes in the values of $\mathrm{L}^{*}$ and $\mathrm{b}^{*}$ coordinates after bleaching treatment. However, after 3 weeks of at-home and 3 sessions of in-office bleaching treatments, CP showed higher $\Delta \mathrm{b}$ than HP. Therefore, CP was more effective to remove the yellowness of teeth and aprismatic enamel not affect this property, once "1E" and "1AE" groups did not differ from each other.

The teeth staining by immersion in tea allows better evaluation of bleaching technique, since this method reproduces the pattern of intrinsic discoloration [1]. During processing of tea, it can be found polyphenolic chromogens, colorless theasinensins, and theaflavins that give red-orange color, in addition to thearubigins with brownish-rust [1, 28].

In this study, after staining a significant change in lightness was observed for dentin, it was also possible to observe a greenness in $\mathrm{a}^{*}$ and a blueness in $\mathrm{b}^{*}$ color parameters. After dental bleaching, dentin appeared lighter over weeks and while of higher delta means in the first 2 evaluation times for treatment with CP compared to HP, the end of treatment the at-home and in-office bleaching methods present effectiveness.

\section{CONCLUSION}

The presence of aprismatic layer affected the results in the first and second week of bleaching with carbamide peroxide. The bleaching treatment was effective for both bleaching protocols at end of treatment. The absence of enamel facilitated the diffusion of bleaching agents, since the organic dentine characteristics that allow more action of free radicals in dental structure.

\section{CONFLICT OF INTEREST}

The authors confirm that this article content has no conflict of interest.

\section{ACKNOWLEDGEMENTS}

Declared none.

\section{REFERENCES}

[1] Sulieman M, Addy M, Rees JS. Development and evaluation of a method in vitro to study the effectiveness of tooth bleaching. J Dent 2003; 31(6): 415-22.

[http://dx.doi.org/10.1016/S0300-5712(03)00069-1] [PMID: 12878024]

[2] Bizhang M, Chun YH, Damerau K, Singh P, Raab WH, Zimmer S. Comparative clinical study of the effectiveness of three different bleaching methods. Oper Dent 2009; 34(6): 635-41. [http://dx.doi.org/10.2341/08-069-C] [PMID: 19953771]

[3] Joiner A. Review of the effects of peroxide on enamel and dentine properties. J Dent 2007; 35(12): 889-96. [http://dx.doi.org/10.1016/j.jdent.2007.09.008] [PMID: 17964705]

[4] Eimar H, Siciliano R, Abdallah MN, et al. Hydrogen peroxide whitens teeth by oxidizing the organic structure. J Dent 2012; 40(Suppl. 2): e25-33. [http://dx.doi.org/10.1016/j.jdent.2012.08.008] [PMID: 22925924]

[5] Joiner A. The bleaching of teeth: a review of the literature. J Dent 2006; 34(7): 412-9. [http://dx.doi.org/10.1016/j.jdent.2006.02.002] [PMID: 16569473]

[6] Wiegand A, Vollmer D, Foitzik M, Attin R, Attin T. Efficacy of different whitening modalities on bovine enamel and dentin. Clin Oral 
Investig 2005; 9(2): 91-7.

[http://dx.doi.org/10.1007/s00784-004-0291-2] [PMID: 15959829]

[7] Dietschi D, Benbachir N, Krejci I. In vitro colorimetric evaluation of the efficacy of home bleaching and over-the-counter bleaching products. Quintessence Int 2010; 41(6): 505-16. [PMID: 20490393]

[8] Viscio D, Gaffar A, Fakhry-Smith S, Xu T. Present and future technologies of tooth whitening. Compend Contin Educ Dent Suppl 2000; 28(28): S36-43. [PMID: 11908346]

[9] Serra MC, Cury JA. The in vitro effect of glass-ionomer cement restoration on enamel subjected to a demineralization and remineralization model. Quintessence Int 1992; 23(2): 143-7.

[PMID: 1641453]

[10] Lima DA, Silva AL, Aguiar FH, et al. In vitro assessment of the effectiveness of whitening dentifrices for the removal of extrinsic tooth stains. Braz Oral Res 2008; 22(2): 106-11. [http://dx.doi.org/10.1590/S1806-83242008000200003] [PMID: 18622478]

[11] Attia ML, Aguiar FH, Mathias P, Ambrosano GM, Fontes CM, Liporoni PC. The effect of coffee solution on tooth color during home bleaching applications. Am J Dent 2009; 22(3): 175-9. [PMID: 19650600]

[12] Camargo MA, Marques MM, de Cara AA. Morphological analysis of human and bovine dentine by scanning electron microscope investigation. Arch Oral Biol 2008; 53(2): 105-8. [http://dx.doi.org/10.1016/j.archoralbio.2007.09.005] [PMID: 17977511]

[13] Laurance-Young P, Bozec L, Gracia L, et al. A review of the structure of human and bovine dental hard tissues and their physicochemical behaviour in relation to erosive challenge and remineralisation. J Dent 2011; 39(4): 266-72. [http://dx.doi.org/10.1016/j.jdent.2011.01.008] [PMID: 21277346]

[14] Sulieman MA. An overview of tooth-bleaching techniques: chemistry, safety and efficacy. Periodontol 2000 2008; 48: 148-69. [http://dx.doi.org/10.1111/j.1600-0757.2008.00258.x] [PMID: 18715362]

[15] Goldberg M, Grootveld M, Lynch E. Undesirable and adverse effects of tooth-whitening products: a review. Clin Oral Investig 2010; 14(1): $1-10$. [http://dx.doi.org/10.1007/s00784-009-0302-4] [PMID: 19543926]

[16] Abouassi T, Wolkewitz M, Hahn P. Effect of carbamide peroxide and hydrogen peroxide on enamel surface: an in vitro study. Clin Oral Investig 2011; 15(5): 673-80.

[http://dx.doi.org/10.1007/s00784-010-0439-1] [PMID: 20623152]

[17] Leonard RH, Sharma A, Haywood VB. Use of different concentrations of carbamide peroxide for bleaching teeth: an in vitro study. Quintessence Int 1998; 29(8): 503-7. [PMID: 9807130]

[18] Dietschi D, Rossier S, Krejci I. In vitro colorimetric evaluation of the efficacy of various bleaching methods and products. Quintessence Int 2006; 37(7): 515-26. [PMID: 16841599]

[19] Raue L, Gersdorff N, Rödiger M, Klein H. New insights in prism orientation within human enamel. Arch Oral Biol 2012; 57(3): 271-6. [http://dx.doi.org/10.1016/j.archoralbio.2011.08.015] [PMID: 21975115]

[20] Ripa LW, Gwinnett AJ, Buonocore MG. The "prismless" outer layer of deciduous and permanent enamel. Arch Oral Biol 1966; 11(1): 41-8. [http://dx.doi.org/10.1016/0003-9969(66)90116-6] [PMID: 5335228]

[21] Gwinnett AJ. The ultrastructure of the "prismless" enamel of permanent human teeth. Arch Oral Biol 1967; 12(3): 381-8. [http://dx.doi.org/10.1016/0003-9969(67)90222-1] [PMID: 5228810]

[22] Berkovitz BK, Holland GR, Moxham BJ. Oral Anatomy, Histology and Embriology. $3^{\text {rd }}$ ed. New York: Mosby 2002

[23] Hanks CT, Fat JC, Wataha JC, Corcoran JF. Cytotoxicity and dentin permeability of carbamide peroxide and hydrogen peroxide vital bleaching materials, in vitro. J Dent Res 1993; 72(5): 931-8. [http://dx.doi.org/10.1177/00220345930720051501] [PMID: 8501291]

[24] Bernardon JK, Sartori N, Ballarin A, Perdigão J, Lopes GC, Baratieri LN. Clinical performance of vital bleaching techniques. Oper Dent 2010; 35(1): 3-10. [http://dx.doi.org/10.2341/09-008CR] [PMID: 20166405]

[25] Trakyali G, Ozdemir FI, Arun T. Enamel colour changes at debonding and after finishing procedures using five different adhesives. Eur J Orthod 2009; 31(4): 397-401. [http://dx.doi.org/10.1093/ejo/cjp023] [PMID: 19460855]

[26] Sulieman M. An overview of bleaching techniques: history, chemistry, safety and legal aspects (part 1). SADJ 2006; 61(7): 304-310, 312. [PMID: 17133792]

[27] Bengel WM. Digital photography and the assessment of therapeutic results after bleaching procedures. J Esthet Restor Dent 2003; 15(Suppl. 1): S21-32. 
[http://dx.doi.org/10.1111/j.1708-8240.2003.tb00315.x] [PMID: 15000901]

[28] Haslam E. Thoughts on thearubigins. Phytochemistry 2003; 64(1): 61-73.

[http://dx.doi.org/10.1016/S0031-9422(03)00355-8] [PMID: 12946406]

\section{C) Públio et al.; Licensee Bentham Open}

This is an open access article licensed under the terms of the Creative Commons Attribution-Non-Commercial 4.0 International Public License (CC BY-NC 4.0) (https://creativecommons.org/licenses/by-nc/4.0/legalcode), which permits unrestricted, non-commercial use, distribution and reproduction in any medium, provided the work is properly cited. 